Historic, Archive Document

Do not assume content reflects current scientific knowledge, policies, or practices. 



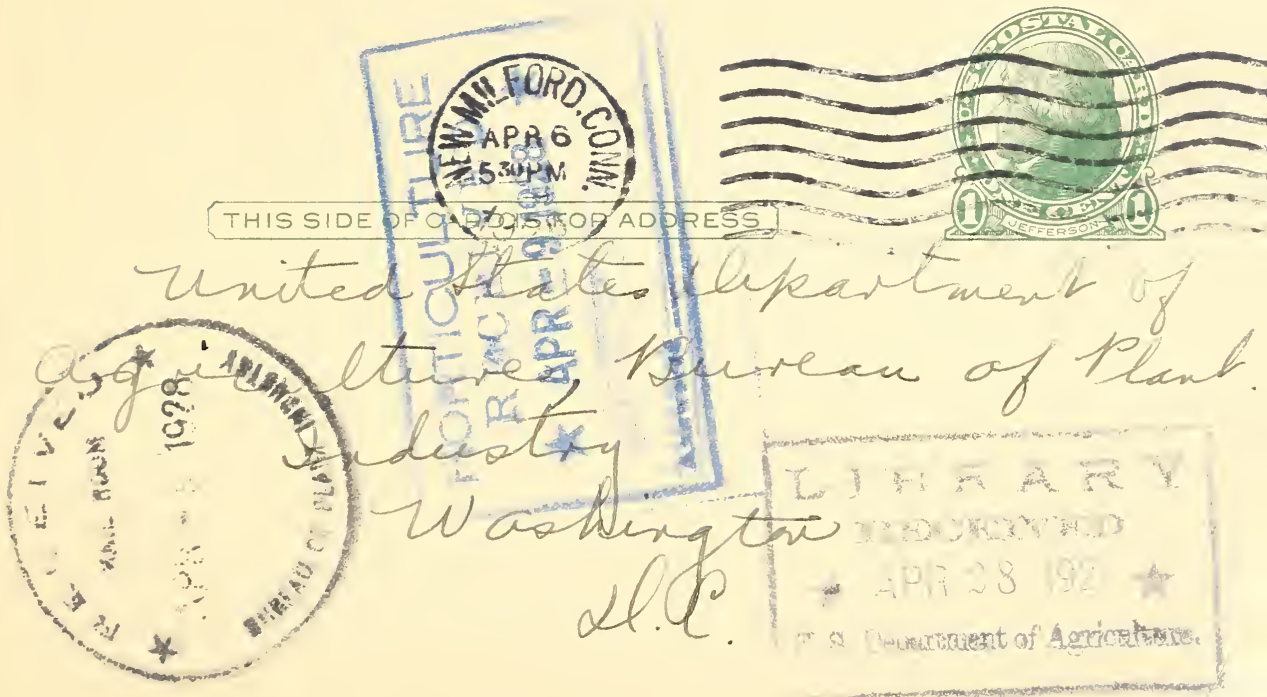


"For a list of garden owners we will send extras with your order"

"They Live" BABY BLUE SPRUCE GARDENS

Raise Raise your own Ornamental Evergreens in your garden or flower beds as borders. Easily and safely transplanted later to your lawn. Will be received in perfect condition by SPECIAL DELIVERY MAIL. Extra fine. Combination orders accepted. 25 at 100 rate.

\section{ORDER BLANK}

BABY BLUE SPRUCE GARDENS, NEW MILFORD, CONN. :

Enclosed find check for the following "Baby Evergreens." Send Prepaid, SPECIAL DELIVERY MAIL.

2 year olds (Any Varieties) \$15 per 100

Colorado Blue Spruce. Englemann Blue Spruce.

Silver Fir. Norway Spruce. Scotch Pine. Japanese Red Pine. Ponderosa Pine. American Hemlock.

Four year old TRANSPLANTS, $\$ 40$ per 100

Picea Pungens (Col. Blue Spruce). Abies Concolor (Silver Fir) Englemann Blue Spruce. American Hemlock.

P. O. 